\title{
Inhibitory effects of adiponectin on platelet-derived growth factor-induced mesangial cell migration
}

\author{
Keisuke Ishizawa ${ }^{1, *}$, Narantungalag Dorjsuren ${ }^{1, *}$, Yuki Izawa-Ishizawa1, Rika Sugimoto², \\ Yasumasa Ikeda ${ }^{1}$, Yoshitaka Kihira ${ }^{1}$, Kazuyoshi Kawazoe ${ }^{2}$, Shuhei Tomita ${ }^{1}$, Koichiro Tsuchiya ${ }^{3}$, \\ Kazuo Minakuchi ${ }^{2}$ and Toshiaki Tamaki ${ }^{1}$ \\ Departments of ${ }^{1}$ Pharmacology, ${ }^{2}$ Clinical Pharmacy and ${ }^{3}$ Medical Pharmacology, The University of Tokushima Graduate School, The Institute of Health \\ Bioscience, 3-18-15, Kuramoto, Tokushima 770-8503, Japan \\ (Correspondence should be addressed to K Ishizawa; Email: ikeisuke@basic.med.tokushima-u.ac.jp) \\ *(K Ishizawa and $\mathrm{N}$ Dorjsuren contributed equally to this work)
}

\begin{abstract}
Adiponectin, an adipocyte-derived hormone, has been involved in metabolic syndrome, a known risk factor for the development of chronic kidney disease (CKD). Recent studies have demonstrated that plasma adiponectin levels are elevated when kidney function declines in patients with CKD. Excessive mesangial cell (MC) turnover is one of the important features of CKD. The aim of the present study is to elucidate the effects of adiponectin on platelet-derived growth factor (PDGF)-induced cell migration and intracellular signaling pathways, in cultured rat MCs (RMCs). PDGF-induced RMC migration was significantly inhibited by the pretreatment of adiponectin. Adiponectin alone had no effect on RMC migration. Big mitogen-activated protein (MAP) kinase 1 (BMK1), p38 MAP kinase, and Akt were activated by PDGF stimulation in a time- and concentration-dependent manner in
\end{abstract}

RMC. Adiponectin alone did not affect BMK1, p38 MAP kinase, and Akt phosphorylations in RMC. PDGF-induced BMK1 and p38 MAP kinase phosphorylations were significantly attenuated by the pretreatment of adiponectin in RMCs. On the other hand, the phosphorylation of Akt by PDGF was not diminished by the pretreatment of adiponectin. Adiponectin had no effects on PDGF-receptor autophosphorylation by PDGF. We also confirmed that PDGF-induced RMC migration was significantly suppressed by siBMK1 transfection or SB203580, a p38 MAP kinase inhibitor. From these findings, it is implied that the elevated plasma adiponectin levels in patients with CKD might play a compensatory role aimed at counteracting renal dysfunction related to MC disorders.

Journal of Endocrinology (2009) 202, 309-316

\section{Introduction}

Metabolic syndrome (MS) is known to be associated with obesity, type 2 diabetes mellitus, and hypertension, and the coexistence of these diseases leads to cardiovascular disease (CVD; Sowers et al. 2001, Lorenzo et al. 2003, Ninomiya et al. 2004, Weiss et al. 2004). In addition, it was reported that MS was a significant risk factor for the development of chronic kidney disease (CKD; Chen et al. 2004, Kurella et al. 2005, Tozawa et al. 2007). It was also showed that adipocytes were capable of releasing numerous vasoactive factors, as well as other cells that present within fat tissues, leading to CKD and CVD in MS (Chu et al. 2001, Yaturu et al. 2007). Adiponectin is a novel adipocyte-derived hormone, which has been proposed to play an important role in the regulation of energy homeostasis and insulin sensitivity (Kadowaki et al. 2006). Plasma adiponectin levels are inversely correlated with obesity (Arita et al. 1999, Asayama et al. 2003), coronary artery disease (Hotta et al. 2000), and insulin resistance (Weyer et al. 2001, Pellme et al. 2003). The effects of adiponectin against atherosclerosis have been demonstrated in previous studies (Matsuda et al. 2002, Ouedraogo et al. 2006). In in vitro studies, adiponectin has been reported to inhibit platelet-derived growth factor (PDGF)- or heparinbinding epidermal growth factor-like growth factor-induced vascular smooth muscle cell (VSMC) migration (Arita et al. 2002). Other studies confirmed that adiponectin knockout mice showed severe neointimal thickening and increased proliferation of VSMC in response to mechanically vascular injury (Kubota et al. 2002, Matsuda et al. 2002). It was reported that plasma adiponectin levels are elevated when renal function is impaired - as early as CKD stage III - and particularly in proteinuric patients (Guebre-Egziabher et al. 2005). Another study demonstrated that plasma adiponectin levels were markedly elevated in patients with end-stage renal disease (Stenvinkel et al. 2004). It has been considered that the rise in plasma adiponectin that occurs during renal function deterioration represents an adaptive response to the altered metabolic profile associated with a high cardiovascular risk in CKD patients. However, the role of elevated plasma adiponectin levels in patients with CKD against renal dysfunction has not been elucidated. 
Cell migration and cell proliferation are fundamental responses of mesangial cells (MCs) to glomerular injury and contribute to the hypercellularity observed in a number of glomerular diseases. Increased glomerular MC turnover is a hallmark of CKD (Striker et al. 1989). MC migration caused by various vasoactive substances is known to be critical for the development of glomerular sclerosis and also for the ECM organization process (Kagami et al. 1999, Kohno et al. 1999, Ishizawa et al. 2004, Takeuchi et al. 2006). In addition, the initial phase of the anti-Thy 1 nephritis model in animals characterized by mesangiolysis is followed by migration and proliferation of MCs (Bagchus et al. 1990). PDGF has been recognized as a major mitogen and one of the most important growth factors, which mediates multiple cellular activities such as cell proliferation and extracellular matrix protein synthesis in a variety types of cells including MCs (Floege et al. 1993, Isaka et al. 1993). Furthermore, the hemodialysis patients showed a significant increase in plasma concentration of PDGF (De Marchi et al. 1996). Previous studies have shown that PDGF-induced cell migration is mediated by mitogen-activated protein (MAP) kinase family members, phosphatidylinositol 3-kinase (PI3K)/Akt and many other kinases (Kagami et al. 2004, Harper et al. 2007). In addition to the classical MAP kinases, i.e. extracellular signal-regulated kinase 1/2 (ERK1/2), JNK, and p38, recently, big MAP kinase 1 (BMK1)/ERK5 was identified as a new MAP kinase family member that is activated by MAP kinase/ERK kinase 5 (MEK5; Lee et al. 1995). Recently, we reported that BMK1 is activated in the glomeruli of diabetic rats and that a high concentration of glucose stimulates BMK1 activation and the proliferation of MCs (Suzaki et al. 2004). PDGF concentration was elevated in the plasma, and its mRNA expression was increased in adipose tissues in obese mice (Pang et al. 2008). Also diabetic obese rats showed increased PDGF protein expression and MC number in glomerulus (Gross et al. 2004). Therefore, in MS, PDGF plays an important role in kidney disease including MC disorder. Although it was reported that adiponectin attenuated PDGFinduced VSMC migration (Arita et al. 2002), there has been no report on whether adiponectin affects the activation of MCs. We hypothesized that elevated adiponectin in patients with CKD was involved in the progression of renal injury, such as migration and proliferation in MCs. The objective of the present study was to investigate the effects of adiponectin on PDGF-induced cell migration and intracellular signaling pathway in cultured rat MCs (RMCs).

\section{Materials and Methods}

\section{Chemicals}

PDGF-BB and SB203580, a p38 MAP kinase inhibitor, were purchased from Sigma. Murine adiponectin, recombinant protein was purchased from Biovendor Laboratory Medicine, Inc. (Modrice, Czech Republic). Anti-phospho-big MAP kinase 1 (BMK1; Thr218/Tyr220) antibody, which recognizes the activated form of BMK1 (Lee et al. 1995), anti-BMK1 antibody, anti-phospho-p38 MAP kinase (Thr180/Tyr182) antibody, anti-p38 MAP kinase antibody, anti-PDGF receptor $\beta$-antibody, phospho-Akt (Ser473) antibody, and Akt antibody were from Cell Signaling Technology, Inc. (Beverly, MA, USA). Antibody for phosphotyrosine (clone 4G10) was from Upstate Biotechnology, Inc. (Lake Placid, NY, USA). All other chemicals were of reagent grade, obtained from commercial sources, and used without further purification.

\section{Cell culture and transfection}

RMCs were isolated from intact glomeruli of 4- to 6-week-old male Sprague-Dawley rats and maintained in $18 \%$ fetal bovine serum (FBS) and RPMI 1640 as described previously (Ishizawa et al. 2004). For the experiments, cells from passages 5 to 9 were used after $24-48 \mathrm{~h}$ of serum depletion. For small interfering RNA (siRNA) assay, RMCs were transiently transfected with lamin A/C siRNA as a control or BMK1-specific siRNA, a cocktail of three siRNAs designed by B-Bridge International, Inc. (Mountain View, CA, USA), by Lipofectamine 2000 (Invitrogen) according to the manufacturer's protocol. Briefly, $5 \mu \mathrm{l}$ Lipofectamine 2000 was diluted in $250 \mu \mathrm{l}$ Opti-MEM I Reduced Serum Medium (Invitrogen), incubated for $5 \mathrm{~min}$ at room temperature, and mixed with a variable amount of BMK1-specific siRNA (final concentrations: $50 \mathrm{nM}$ ). After 30-min incubation at room temperature, the mixture was added to each well of RMCs, which were plated into sixwell plates. After $24 \mathrm{~h}$, cells were washed and fresh medium that contained 10\% FBS was added. Thirty-six hours after transfection, cells were treated with or without PDGF and/or adiponectin.

\section{RMC migration assays}

To assess cell migration, a modified Boyden chamber assay was performed with minor modification to the method described previously (Ishizawa et al. 2004). The assay was performed using Transwell chambers $(6.5 \mathrm{~mm}$, model 3422 ; Costar, Cambridge, MA, USA) with an $8 \mu \mathrm{m}$ pore polycarbonate membrane. The underside of the polycarbonate membrane was coated with $5 \mu \mathrm{g} / \mathrm{ml}$ collagen I rat tail (3.78 mg/ml, model 35-4236; Collaborative Biochemical Products, Bedford, MA, USA) overnight at $4{ }^{\circ} \mathrm{C}$. Then the lower chamber was blocked with RPMI $1640 / 0 \cdot 1 \%$ BSA for $30 \mathrm{~min}$ at room temperature. Quiescent control cells or siRNA-transfected cells were harvested, washed, and suspended in serum-free RPMI 1640. Cells were added to the upper chamber of the Transwell at $5 \times 10^{5}$ cells in $100 \mu \mathrm{l} /$ well. A total of $600 \mu \mathrm{l}$ serum-free RPMI 1640 was added to the lower chamber and then pretreated with or without adiponectin or SB203580 in the lower chamber for $30 \mathrm{~min}$ at $37^{\circ} \mathrm{C}$ followed by treatment with or without PDGF in the lower chamber, and cells were allowed to migrate at $37^{\circ} \mathrm{C}$. After $6 \mathrm{~h}$ of incubation, the nonmigratory 
cells were removed from the upper surface of the membrane by scraping off with cotton swabs. Membrane was fixed with methanol, stained with Diff-Quik solution (Baxter, McGaw Park, IL, USA), and allowed to air-dry at room temperature. Then, the membrane was excised from the plastic supports with a sharp scalpel and mounted on a glass slide using Permount (Sigma Chemical). Cells that had migrated from the upper to the lower side of the membrane were counted at $400 \times$ magnification in 10 microscope fields per filter.

\section{Preparation of cell lysate for immunoprecipitation} and immunoblotting

Quiescent control cells or siRNA-transfected cells were treated with or without PDGF, adiponectin, and SB203580 at the indicated concentrations for the indicated periods of time. Cells were pretreated with adiponectin or SB203580 at the indicated concentration for $30 \mathrm{~min}$. Then the cells were stimulated with $10 \mathrm{ng} / \mathrm{ml}$ PDGF for $5 \mathrm{~min}$ for p38 MAP kinase phosphorylation and $10 \mathrm{~min}$ for BMK1 and Akt phosphorylations. Then, incubation media were discarded, and the cells were lysed with cell lysis buffer $(20 \mathrm{mM}$ Tris- $\mathrm{HCl}$ (pH 7•4), $150 \mathrm{mM} \mathrm{NaCl}, 1 \mathrm{mM}$ EDTA, $1 \mathrm{mM}$ EGTA, 1\% Triton $\mathrm{X}-100,2.5 \mathrm{mM}$ sodium pyrophosphate, $1 \mathrm{mM}$ $\beta$-glycerophosphate, $1 \mathrm{mM}$ sodium orthovanadate, $1 \mu \mathrm{g} / \mathrm{ml}$ leupeptin, and $1 \mathrm{mM}$ phenylmethylsulfonyl fluoride). After freeze-thawing, lysed cells were transferred to microcentrifuge tubes, sonicated (Handy Sonic UR-20 P; Tomy Seiko Co., $\mathrm{Ltd}$, Tokyo, Japan) on ice, and centrifuged at $20000 \boldsymbol{g}$ for $20 \mathrm{~min}$ at $4{ }^{\circ} \mathrm{C}$. The protein concentrations of the supernatants were measured with a protein assay kit (Bio-Rad) and stored at $-80{ }^{\circ} \mathrm{C}$ until performing immunoprecipitation and immunoblotting.

\section{Immunoprecipitation and immunoblotting}

For immunoprecipitation, lysates containing equal amounts of protein were incubated with anti-PDGF receptor $\beta$-antibody overnight and then incubated with protein $A / G$ PLUS-agarose beads for $2 \mathrm{~h}$ on a roller system at $4{ }^{\circ} \mathrm{C}$. After immunoprecipitation, samples were subjected to immunoblot assay using anti-phosphotyrosine antibody (clone 4G10). For western blot analysis, cell lysates were subjected to SDS-PAGE, and proteins were transferred to nitrocellulose membranes (Hybond-ECL; Amersham Pharmacia Biotech), as described previously. The membranes were blocked for $1 \mathrm{~h}$ at room temperature with 5\% BSA. The blots were then incubated for $12 \mathrm{~h}$ with 4G10 antibody, anti-phospho-specific BMK1, anti-phospho-specific p38 MAP kinase, and antiphospho-specific Akt followed by incubation for $1 \mathrm{~h}$ with a secondary antibody (HRP conjugated). Immunoreactive bands were visualized using enhanced chemiluminescence (ECL; Amersham Pharmacia Biotech) and were quantified by densitometry in the linear range of film exposure using an Epson Perfection 2580 Photo Scanner (Epson America, Inc., Long Beach, CA, USA) and image $1.37 \mathrm{v}$ software.

\section{Statistical analysis}

Values are reported as the means \pm s.D. from experiments performed on five different occasions. Two-way ANOVA was used to determine the significance among groups, after which a modified $t$-test with Bonferroni's post hoc test was used for comparisons between individual groups. A value of $P<0 \cdot 05$ was considered to be statistically significant.
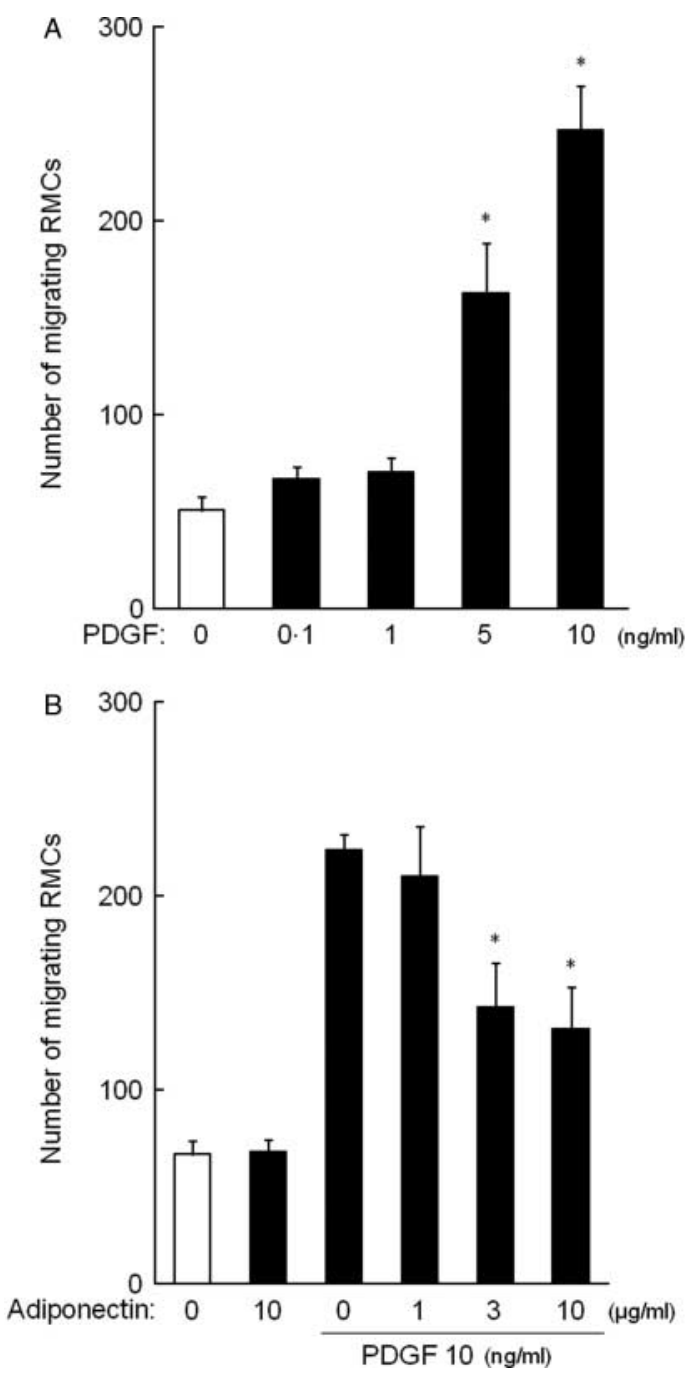

Figure 1 PDGF-induced RMC migration. (A) Concentrationdependent increase in PDGF-induced RMC migration. Cells were treated with indicated concentration of PDGF for $6 \mathrm{~h}$. And then, modified Boyden chamber assay was performed as described under Materials and Methods (values are the means \pm s.D., $n=5, * P<0 \cdot 05$ ). (B) Adiponectin concentrationdependent suppression of PDGF-induced RMC migration. Cells were treated with indicated concentration of adiponectin 30 min prior to treatment with PDGF $(10 \mathrm{ng} / \mathrm{ml})$ for $6 \mathrm{~h}$ (values are the means \pm s.D., $n=5, * P<0 \cdot 05$ versus PDGF $10 \mathrm{ng} / \mathrm{ml}$ without adiponectin). 


\section{Results}

\section{Adiponectin inhibited PDGF-induced RMC migration}

We confirmed that PDGF increased RMC migration in a concentration-dependent manner $(0 \cdot 1-10 \mathrm{ng} / \mathrm{ml}$; Fig. 1A) by modified Boyden chamber assay as described in the Materials and Methods section. We also discovered that stimulation with adiponectin alone had no effects on RMC migration at any
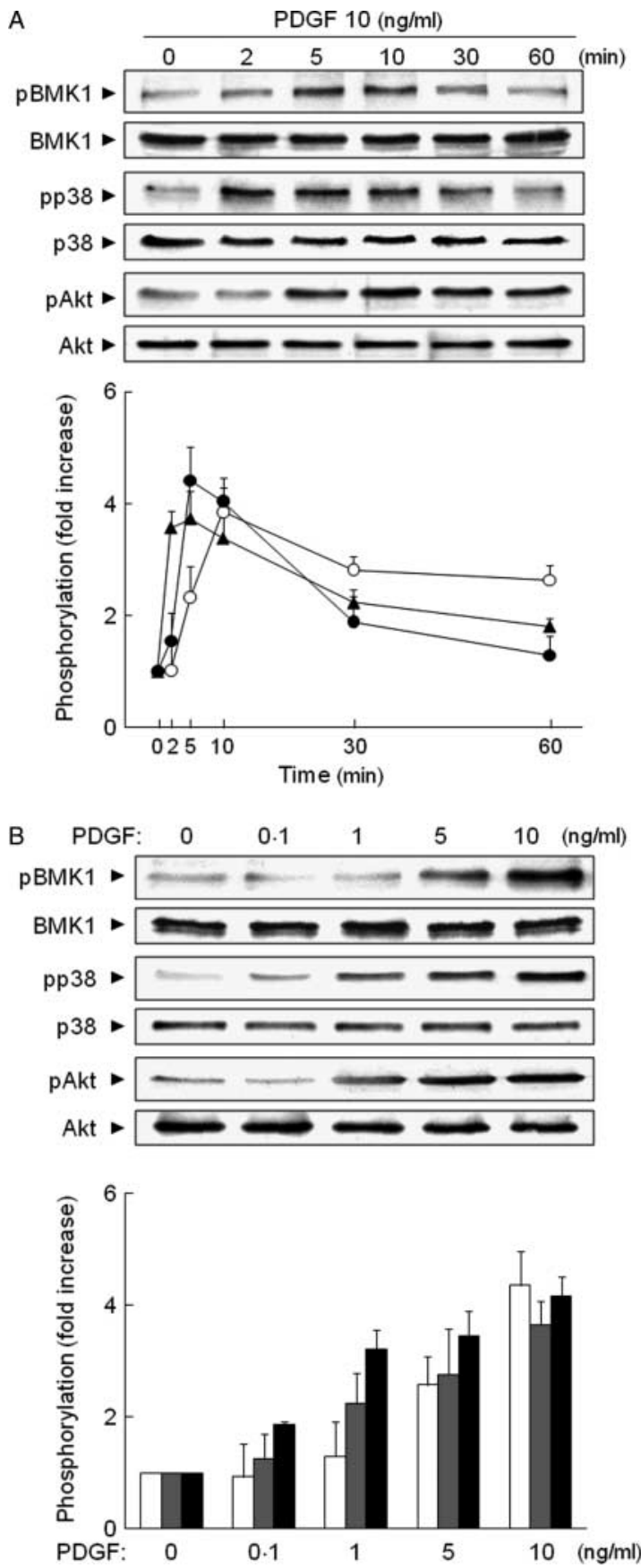

Journal of Endocrinology (2009) 202, 309-316 physiological doses $(0 \cdot 1,0 \cdot 3,1,3$, and $10 \mu \mathrm{g} / \mathrm{ml}$; data not shown). To examine whether adiponectin affect PDGFinduced RMC migration, growth-arrested RMCs were treated with or without adiponectin $(1,3$ and $10 \mu \mathrm{g} / \mathrm{ml})$ $30 \mathrm{~min}$ prior to stimulation with PDGF $(10 \mathrm{ng} / \mathrm{ml}, 6 \mathrm{~h})$. As shown in Fig. 1B, adiponectin pretreatment significantly suppressed PDGF-induced RMC migration (3 and $10 \mu \mathrm{g} / \mathrm{ml}$ ).

Adiponectin attenuated PDGF-induced phosphorylation of BMK1 and 38 MAP kinase, but not Akt

To evaluate the relative magnitude of BMK1, p38 MAP kinase, and Akt activities by PDGF, RMCs were exposed to PDGF $(10 \mathrm{ng} / \mathrm{ml})$ for the indicated periods of time. PDGF rapidly activated p38 MAP kinase (peak at $5 \mathrm{~min}$ ) and then gradually declined (Fig. 2A). BMK1 and Akt were activated within $10 \mathrm{~min}$ by PDGF stimulation (peak at 5 and $10 \mathrm{~min}$ respectively; Fig. 2A). The phosphorylations of these kinases showed PDGF concentration-dependent increase at each peak periods of time (Fig. 2B). As shown in Fig. 3, exposure with adiponectin alone had no effects on the phosphorylation of BMK1, p38 MAP kinase, and Akt in RMCs. However, pretreatment of adiponectin (3 and $10 \mu \mathrm{g} /$ ml) significantly inhibited PDGF-induced phosphorylation of BMK1 and p38 MAP kinase, but not Akt. From these results, it was suggested that the inhibitory effects of adiponectin on PDGF-induced RMC migration was involved in the suppression of BMK1 and p38 MAP kinase phosphorylations. Furthermore, we confirmed that adiponectin did not suppress PDGF receptor autophosphorylation by PDGF stimulation (Fig. 4). These findings indicated that the inhibition of PDGF-induced kinase activities by adiponectin was the intracellular event in RMCs.

PDGF-induced RMC migration was suppressed by siBMK1 transfection or SB203580

To confirm that PDGF-induced RMC migration was mediated by BMK1 and p38 MAP kinase activations, siBMK1 transfection technique or pretreatment with SB203580, a p38 MAP kinase inhibitor, was used for the

Figure 2 (A) Time courses and (B) concentration response of PDGFinduced BMK1, p38 MAP kinase, and Akt phosphorylations in RMCs. Cells were treated with $10 \mathrm{ng} / \mathrm{ml}$ PDGF for the indicated periods of time $(\mathrm{A})$ and were stimulated with the indicated concentrations of PDGF for 5 min for BMK1 and p38 MAP kinase, and $10 \mathrm{~min}$ for Akt (B). The cell lysates (50 $\mu \mathrm{g}$ protein) at the indicated time points were subjected to western blot analysis. No significant differences in the amounts of total BMK1, p38 MAP kinase, and Akt were observed in western blot analysis with antiBMK1, anti-p38 MAP kinase, and anti-Akt antibodies respectively. Upper panels show the representative blots. Lower graphs show the results of densitometric analysis. Closed circle, BMK1; triangle, p38 MAP kinase; open circle, Akt (A); open column, BMK1; gray column, p38 MAP kinase; solid column, Akt (B). Values were normalized by arbitrarily setting the densitometry of control cells (time $=0$, without PDGF) to $1 \cdot 0$. 
inhibition of BMK1 and p38 MAP kinase respectively as described in Materials and Methods. The cells were transfected with BMK1 siRNA $(5,50 \mathrm{nM})$ and lamin siRNA $(50 \mathrm{nM})$ as a negative control. The expression of BMK1 protein was significantly suppressed in RMCs treated with BMK1 siRNA, not lamin siRNA (Fig. 5A). In siBMK1-transfected RMCs, PDGF-induced BMK1 phosphorylation was significantly decreased, but phosphorylations of p38 and Akt were not affected, compared with PDGF-stimulated mocktransfected control cells (Fig. 5B). Lamin siRNA transfection had no effects on phosphorylations of BMK1, p38, and Akt. The pretreatment with $1 \mu \mathrm{M}$ SB203580 significantly suppressed PDGF-induced p38 MAP kinase phosphorylation in RMCs. (Fig. 5C). It was reported that SB203580 is not specific to $\mathrm{p} 38$ and that the higher concentration of SB20358 can also block Akt activation (IC50 3-5 $\mu \mathrm{M}$; Lali et al. 2000). However, it was confirmed that $1 \mu \mathrm{M}$ SB203580 had effects neither on PDGF-induced BMK1 nor on Akt phosphorylation in our present sets of experiments (Fig. 5C).

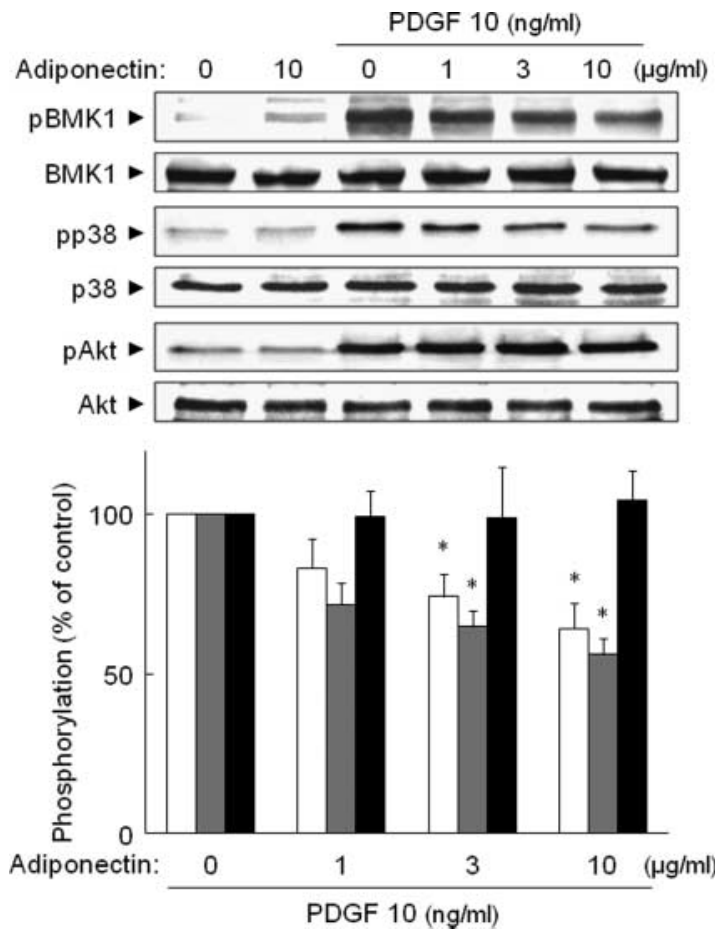

Figure 3 Effects of adiponectin on PDGF-induced BMK1, p38 MAP kinase, and Akt phosphorylations in RMCs. Cells were pretreated with indicated concentration of adiponectin $30 \mathrm{~min}$ prior to treatment with PDGF $(10 \mathrm{ng} / \mathrm{ml})$. The cell lysates $(50 \mu \mathrm{g}$ protein) at the indicated time points were subjected to western blot analysis. No significant differences in the amounts of total BMK1, p38 MAP kinase, and Akt were observed in western blot analysis with antiBMK1, anti-p38 MAP kinase, and anti-Akt antibodies respectively. Upper panels show the representative blots. Lower graphs show the results of densitometric analysis. Open column, BMK1; gray column, p38 MAP kinase; solid column, Akt values were normalized by arbitrarily setting the densitometry of control cells (without PDGF) to $100 \%$ (values are the means \pm s.D., $n=5$,

$* P<0 \cdot 05$ versus PDGF $10 \mathrm{ng} / \mathrm{ml}$ without adiponectin).
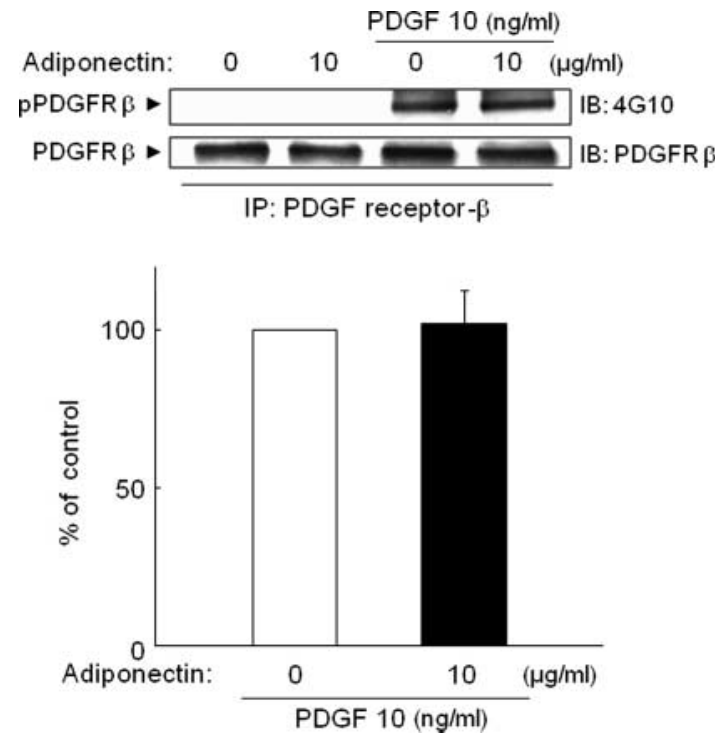

Figure 4 Effects of adiponectin on PDGF-induced PDGF receptor tyrosine phosphorylation in RMCs. Cells were treated with adiponectin $30 \mathrm{~min}$ prior to treatment with PDGF $(10 \mathrm{ng} / \mathrm{ml})$. Tyrosine phosphorylation of PDGF receptor was measured by immunoprecipitation assay with phosphotyrosine-specific antibody, 4G10 as described in Materials and Methods. Upper panel shows the representative blot. Lower graph shows the results of densitometric analysis. The cell lysates ( $50 \mu \mathrm{g}$ protein) at the indicated time points were subjected to western blot analysis. Values were normalized by arbitrarily setting the densitometry of control cells (without PDGF) to $100 \%$ (values are the means \pm s.D., $n=5)$. PDGFR, PDGF receptor; IP, immunoprecipitation; IB, immunoblotting.

As shown in Fig. 5D, both siBMK1 transfection and SB203580 pretreatment significantly inhibited PDGF-induced RMC migration in part. In addition, the combination of siBMK1 transfection and SB203580 almost completely inhibited RMC migration to the control level. Lamin siRNA transfection had no effects on PDGF-induced RMC migration. From these results, it was suggested that the combination of siBMK1 transfection and SB203580 plays a synergistic inhibitory effect on PDGF-induced RMC migration.

\section{Discussion}

In the present study, we demonstrated that adiponectin inhibited PDGF-induced RMC migration through the suppression of BMK1 and p38 MAP kinase activations. Furthermore, adiponectin selectively inhibited BMK1 and p38 MAP kinase pathway, not Akt pathway, stimulated by PDGF in RMCs. From these results, it was suggested that adiponectin can attenuate the renal dysfunction related with MC disorders.

PDGF is a mitogen that causes MC migration, which plays an important role in the changes in glomerular morphology in CKD. We have confirmed in this study that PDGF causes RMC migration in concentration-dependent manner 


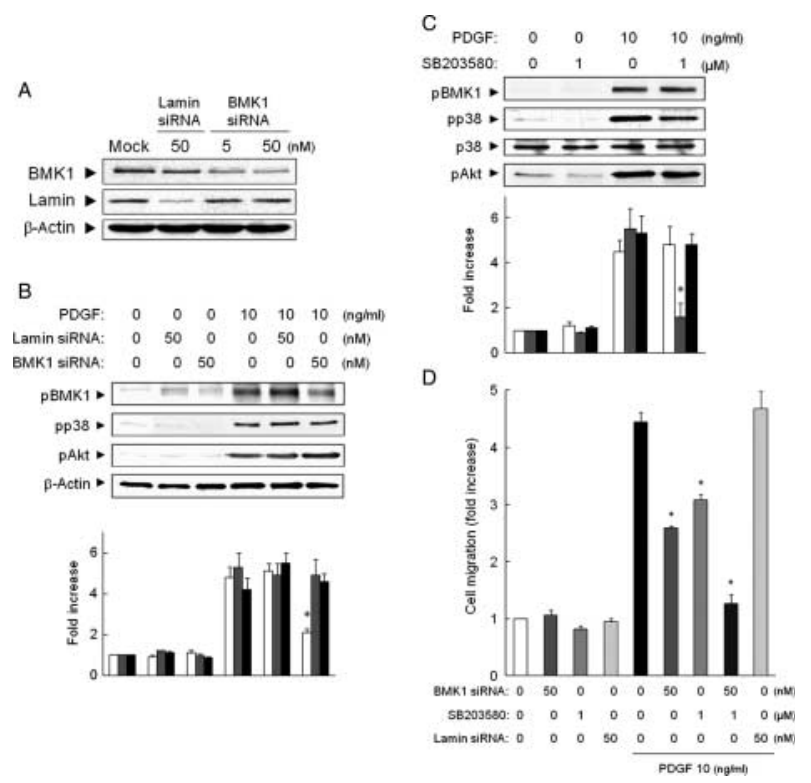

Figure 5 Effects of siBMK1 transfection and SB203580 on PDGFinduced RMC migration. Cells were transfected with $50 \mathrm{nM}$ siBMK1 or pretreated with $1 \mu \mathrm{M}$ SB203580 for $30 \mathrm{~min}$, followed by $10 \mathrm{ng} / \mathrm{ml}$ PDGF stimulation as described in Materials and Methods. (A) BMK1 expression was measured by western blotting analysis. Cells were transfected with BMK1 siRNA and lamin siRNA as a negative control. No significant differences in the amount of $\beta$-actin were observed in lysates by immunoblotting with anti- $\beta$-actin antibody. (B) PDGF-induced BMK1, p38 MAP kinase, and Akt phosphorylation in RMCs. No significant differences in the amount of $\beta$-actin were observed in lysates by immunoblotting with anti- $\beta$-actin antibody. Panels show the representative blots. The cell lysates (50 $\mu$ g protein) at the indicated time points were subjected to western blot analysis. Upper panels show the representative blots. Lower graphs show the results of densitometric analysis. Values were normalized by arbitrarily setting the densitometry of control cells (time $=0$, without PDGF) to $1 \cdot 0$ (values are the means \pm s.D., $n=5, * P<0 \cdot 05$ versus the values of PDGF stimulation in mocktransfected cells). Open column, BMK1; gray column, p38 MAP kinase; solid column, Akt (C) PDGF-induced p38 MAP kinase phosphorylation in RMCs. No significant differences in the amount p38 MAP kinase were observed in lysates by immunoblotting with anti-p38 MAP kinase antibody. Panels show the representative blots. The cell lysates ( $50 \mu \mathrm{g}$ protein) at the indicated time points were subjected to western blot analysis. Upper panels show the representative blots. Lower graphs show the results of densitometric analysis. Values were normalized by arbitrarily setting the densitometry of control cells (time $=0$, without PDGF) to $1 \cdot 0$ (values are the means \pm s.D., $n=5, * P<0 \cdot 05$ versus PDGF $10 \mathrm{ng} / \mathrm{ml}$ without SB203580). Open column, BMK1; gray column, p38 MAP kinase; solid column, Akt (D) PDGF-induced RMC migration. Values were normalized by arbitrarily setting the fold increases in the migration of control cells (without PDGF treatment) to $1 \cdot 0$ (values are the means \pm s.D., $n=5, * P<0 \cdot 05$ versus PDGF $10 \mathrm{ng} / \mathrm{ml}$ alone).

demonstrating increased MC proliferation and glomerular PDGF expression in the five out of six nephrectomized rats, which were well-established models of CKD (Floege et al. 1992). These findings suggest that PDGF-induced RMC disorders in the glomeruli may contribute to glomerular injury leading to CKD. As shown in Fig. 1B, we clarified that PDGF-induced RMC migration was significantly suppressed by pretreatment with adiponectin. It was reported that adiponectin associated with PDGF, and that adiponectin blocked the binding between PDGF and its receptor (Arita et al. 2002). However, as we have shown in Fig. 4, adiponectin had no effect on PDGF receptor autophosphorylation by PDGF stimulation. These results suggest that the inhibitory effects of adiponectin on PDGF-induced kinase activities are the intracellular event in RMCs. To the best of our knowledge, this is the first report about the inhibitory effects of adiponectin on PDGF-induced RMC migration. These findings indicate that adiponectin might have beneficial effects against renal dysfunction including $\mathrm{MC}$ disorders. In some studies, it was reported that plasma adiponectin levels were elevated in patients with CKD (Stenvinkel et al. 2004, Guebre-Egziabher et al. 2005). It is suggested that the elevated plasma adiponectin levels can work as a compensatory mechanism to attenuate the progression of glomerular dysfunction in the patients with CKD.

To explore these inhibitory mechanisms of adiponectin on cell migration, we examined the effect of adiponectin on the PDGF-induced cellular signaling involved in RMC migration. It has been reported that PDGF-induced MC migration is mediated by MAP kinases, PI3K/Akt, and many other kinases (Kagami et al. 2004, Harper et al. 2007). As shown in Fig. 2A and B, BMK1, p38 MAP kinase, and Akt were activated by PDGF in RMCs in a time- and concentration-dependent manner. We also revealed that adiponectin attenuated PDGF-induced BMK1 and p38 MAP kinase phosphorylations, but not Akt in RMCs (Fig. 3). Therefore, we confirmed that siBMK1 transfection or SB203580 suppressed PDGF-induced RMC migration (Fig. 5C). These findings indicate that PDGF-induced RMC migration is mediated by BMK1 and p38 MAP kinase activations. In several studies, it was shown that the activation of BMK1 led to cell proliferation, morphogenesis, antiapoptosis, and so on (Karihaloo et al. 2001, Pi et al. 2004, Barros \& Marshall 2005). We have already demonstrated that BMK1 is activated in the glomeruli of diabetic rats and that a high concentration of glucose stimulates RMC proliferation via BMK1 activation (Suzaki et al. 2004). Moreover, we have also reported that PDGF-induced BMK1 activation leads to VSMC migration (Izawa et al. 2007). These reports support our new findings that BMK1 activation mediates PDGFinduced cell migration in RMCs. Meanwhile, p38 MAP kinase also has a critical role in various cellular functions including apoptosis. It was reported that increased p38 MAP kinase signaling was a feature of human and experimental diabetic nephropathy (Adhikary et al. 2004). We have already reported that SB203580, a p38 MAP kinase inhibitor, suppressed cell migration induced by vascular endothelial growth factor in human umbilical vein endothelial cells (Ali et al. 2005). In addition, consistent with our present findings, it has been reported that PDGF-induced p38 ffMAP kinase activation regulated cell migration in VSMCs 
(Zhan et al. 2003, Yamaguchi et al. 2004). We have already demonstrated that adiponectin inhibited IGF-1-induced cell migration through suppression of ERK1/2 activation, which might be implicated in AMPK activation in VSMCs (Motobayashi et al. 2009). However, detailed mechanisms including signaling crosstalk have not yet been studied in RMCs. Thus, to further elucidate mechanisms of adiponectin, effects on various cellular responses by PDGF through the suppression of BMK1 and p38 MAP kinase have importance.

In conclusion, we have demonstrated the inhibitory effects of adiponectin on PDGF-induced MC migration. These findings suggest that the elevated plasma adiponectin levels in patients with CKD might play a compensatory role aimed at counteracting renal dysfunction. Further studies to elucidate the precise mechanisms by which adiponectin exerts potential therapeutic effects on CKD via the suppression of $\mathrm{MC}$ disorder are currently under way.

\section{Declaration of interest}

The authors declare that there is no conflict of interest that would prejudice the impartiality of this scientific work.

\section{Funding}

This work was supported by Knowledge Cluster Initiative from Ministry of Education, Culture, Sports, Science, and Technology of Japan (to T T).

\section{References}

Adhikary L, Chow F, Nikolic-Paterson DJ, Stambe C, Dowling J, Atkins RC \& Tesch GH 2004 Abnormal p38 mitogen-activated protein kinase signalling in human and experimental diabetic nephropathy. Diabetologia 47 1210-1222.

Ali N, Yoshizumi M, Fujita Y, Izawa Y, Kanematsu Y, Ishizawa K, Tsuchiya K, Yano S, Sone S \& Tamaki T 2005 A novel Src kinase inhibitor, M475271, inhibits VEGF-induced human umbilical vein endothelial cell proliferation and migration. Journal of Pharmacological Sciences 98 130-141.

Arita Y, Kihara S, Ouchi N, Takahashi M, Maeda K, Miyagawa J, Hotta K, Shimomura I, Nakamura T, Miyaoka K et al. 1999 Paradoxical decrease of an adipose-specific protein, adiponectin, in obesity. Biochemical and Biophysical Research Communications 257 79-83.

Arita Y, Kihara S, Ouchi N, Maeda K, Kuriyama H, Okamoto Y, Kumada M, Hotta K, Nishida M, Takahashi M et al. 2002 Adipocyte-derived plasma protein adiponectin acts as a platelet-derived growth factor-BB-binding protein and regulates growth factor-induced common postreceptor signal in vascular smooth muscle cell. Circulation 105 2893-2898.

Asayama K, Hayashibe H, Dobashi K, Uchida N, Nakane T, Kodera K, Shirahata A \& Taniyama M 2003 Decrease in serum adiponectin level due to obesity and visceral fat accumulation in children. Obesity Research $\mathbf{1 1}$ 1072-1079.

Bagchus WM, Jeunink MF \& Elema JD 1990 The mesangium in anti-Thy-1 nephritis. Influx of macrophages, mesangial cell hypercellularity, and macromolecular accumulation. American Journal of Pathology 137 215-223.

Barros JC \& Marshall CJ 2005 Activation of either ERK1/2 or ERK5 MAP kinase pathways can lead to disruption of the actin cytoskeleton. Journal of Cell Science 118 1663-1671.

Chen J, Muntner P, Hamm LL, Jones DW, Batuman V, Fonseca V, Whelton PK \& He J 2004 The metabolic syndrome and chronic kidney disease in US adults. Annals of Internal Medicine 140 167-174.
Chu NF, Spiegelman D, Hotamisligil GS, Rifai N, Stampfer M \& Rimm EB 2001 Plasma insulin, leptin, and soluble TNF receptors levels in relation to obesity-related atherogenic and thrombogenic cardiovascular disease risk factors among men. Atherosclerosis 157 495-503.

Floege J, Burns MW, Alpers CE, Yoshimura A, Pritzl P, Gordon K, Seifert RA, Bowen-Pope DF, Couser WG \& Johnson RJ 1992 Glomerular cell proliferation and PDGF expression precede glomerulosclerosis in the remnant kidney model. Kidney International 41 297-309.

Floege J, Eng E, Young BA, Alpers CE, Barrett TB, Bowen-Pope DF \& Johnson RJ 1993 Infusion of platelet-derived growth factor or basic fibroblast growth factor induces selective glomerular mesangial cell proliferation and matrix accumulation in rats. Journal of Clinical Investigation 92 2952-2962.

Gross ML, Ritz E, Schoof A, Adamczak M, Koch A, Tulp O, Parkman A, El-Shakmak A, Szabo A \& Amann K 2004 Comparison of renal morphology in the streptozotocin and the SHR/N-cp models of diabetes. Laboratory Investigation 84 452-464.

Guebre-Egziabher F, Bernhard J, Funahashi T, Hadj-Aissa A \& Fouque D 2005 Adiponectin in chronic kidney disease is related more to metabolic disturbances than to decline in renal function. Nephrology, Dialysis, Transplantation 20 129-134.

Harper L, Kashiwagi Y, Pusey CD, Hendry BM \& Domin J 2007 Plateletderived growth factor reorganizes the actin cytoskeleton through 3-phosphoinositide-dependent and 3-phosphoinositide-independent mechanisms in human mesangial cells. Nephron. Physiology 107 p45-p56.

Hotta K, Funahashi T, Arita Y, Takahashi M, Matsuda M, Okamoto Y, Iwahashi $\mathrm{H}$, Kuriyama $\mathrm{H}$, Ouchi N, Maeda K et al. 2000 Plasma concentrations of a novel, adipose-specific protein, adiponectin, in type 2 diabetic patients. Arteriosclerosis, Thrombosis, and Vascular Biology 20 1595-1599.

Isaka Y, Fujiwara Y, Ueda N, Kaneda Y, Kamada T \& Imai E 1993 Glomerulosclerosis induced by in vivo transfection of transforming growth factor-beta or platelet-derived growth factor gene into the rat kidney. Journal of Clinical Investigation 92 2597-2601.

Ishizawa K, Yoshizumi M, Tsuchiya K, Houchi H, Minakuchi K, Izawa Y, Kanematsu Y, Kagami S, Hirose M \& Tamaki T 2004 Dual effects of endothelin-1 (1-31): induction of mesangial cell migration and facilitation of monocyte recruitment through monocyte chemoattractant protein-1 production by mesangial cells. Hypertension Research 27 433-440.

Izawa Y, Yoshizumi M, Ishizawa K, Fujita Y, Kondo S, Kagami S, Kawazoe K, Tsuchiya K, Tomita S \& Tamaki T 2007 Big mitogen-activated protein kinase1 (BMK1)/ERK5 is involved in platelet-derived growth factor (PDGF)-induced vascular smooth muscle cell migration. Hypertension Research 30 1107-1117.

Kadowaki T, Yamauchi T, Kubota N, Hara K, Ueki K \& Tobe K 2006 Adiponectin and adiponectin receptors in insulin resistance, diabetes, and the metabolic syndrome. Journal of Clinical Investigation 116 1784-1792.

Kagami S, Kondo S, Loster K, Reutter W, Kuhara T, Yasutomo K \& Kuroda Y 1999 Alpha1beta1 integrin-mediated collagen matrix remodeling by rat mesangial cells is differentially regulated by transforming growth factor-beta and platelet-derived growth factor-BB. Journal of the American Society of Nephrology 10 779-789.

Kagami S, Urushihara M, Kitamura A, Kondo S, Hisayama T, Kitamura M, Loster K, Reutter W \& Kuroda Y 2004 PDGF-BB enhances alpha1beta1 integrin-mediated activation of the ERK/AP-1 pathway involved in collagen matrix remodeling by rat mesangial cells. Journal of Cellular Physiology 198 470-478.

Karihaloo A, O'Rourke DA, Nickel C, Spokes K \& Cantley LG 2001 Differential MAPK pathways utilized for HGF- and EGF-dependent renal epithelial morphogenesis. Journal of Biological Chemistry 276 9166-9173.

Kohno M, Yasunari K, Minami M, Kano H, Maeda K, Mandal AK, Inoki K, Haneda M \& Yoshikawa J 1999 Regulation of rat mesangial cell migration by platelet-derived growth factor, angiotensin II, and adrenomedullin. Journal of the American Society of Nephrology 10 2495-2502.

Kubota N, Terauchi Y, Yamauchi T, Kubota T, Moroi M, Matsui J, Eto K, Yamashita T, Kamon J, Satoh H et al. 2002 Disruption of adiponectin causes insulin resistance and neointimal formation. Journal of Biological Chemistry $27725863-25866$. 
Kurella M, Lo JC \& Chertow GM 2005 Metabolic syndrome and the risk for chronic kidney disease among nondiabetic adults. Journal of the American Society of Nephrology 16 2134-2140.

Lali FV, Hunt AE, Turner SJ \& Foxwell BM 2000 The pyridinyl imidazole inhibitor SB203580 blocks phosphoinositide-dependent protein kinase activity, protein kinase $\mathrm{B}$ phosphorylation, and retinoblastoma hyperphosphorylation in interleukin-2-stimulated T cells independently of p38 mitogen-activated protein kinase. Journal of Biological Chemistry 275 7395-7402.

Lee JD, Ulevitch RJ \& Han J 1995 Primary structure of BMK1: a new mammalian map kinase. Biochemical and Biophysical Research Communications 213 715-724.

Lorenzo C, Okoloise M, Williams K, Stern MP \& Haffner SM 2003 The metabolic syndrome as predictor of type 2 diabetes: the San Antonio heart study. Diabetes Care 26 3153-3159.

De Marchi S, Falleti E, Giacomello R, Stel G, Cecchin E, Sepiacci G, Bortolotti N, Zanello F, Gonano F \& Bartoli E 1996 Risk factors for vascular disease and arteriovenous fistula dysfunction in hemodialysis patients. Journal of the American Society of Nephrology 7 1169-1177.

Matsuda M, Shimomura I, Sata M, Arita Y, Nishida M, Maeda N, Kumada M, Okamoto Y, Nagaretani H, Nishizawa H et al. 2002 Role of adiponectin in preventing vascular stenosis. The missing link of adipo-vascular axis. Journal of Biological Chemistry 277 37487-37491.

Motobayashi Y, Izawa-Ishizawa Y, Ishizawa K, Orino S, Yamaguchi K, Kawazoe K, Hamano S, Tsuchiya K, Tomita S \& Tamaki T 2009 Adiponectin inhibits insulin-like growth factor-1-induced cell migration by the suppression of extracellular signal-regulated kinase $1 / 2$ activation, but not Akt in vascular smooth muscle cells. Hypertension Research 32 188-193.

Ninomiya JK, L'Italien G, Criqui MH, Whyte JL, Gamst A \& Chen RS 2004 Association of the metabolic syndrome with history of myocardia infarction and stroke in the Third National Health and Nutrition Examination Survey. Circulation 109 42-46.

Ouedraogo R, Wu X, Xu SQ, Fuchsel L, Motoshima H, Mahadev K, Hough K, Scalia R \& Goldstein BJ 2006 Adiponectin suppression of high-glucose-induced reactive oxygen species in vascular endothelial cells: evidence for involvement of a cAMP signaling pathway. Diabetes 55 1840-1846.

Pang C, Gao Z, Yin J, Zhang J, Jia W \& Ye J 2008 Macrophage infiltration into adipose tissue may promote angiogenesis for adipose tissue remodeling in obesity. American Journal of Physiology. Endocrinology and Metabolism 295 E313-E322.

Pellme F, Smith U, Funahashi T, Matsuzawa Y, Brekke H, Wiklund O, Taskinen MR \& Jansson PA 2003 Circulating adiponectin levels are reduced in nonobese but insulin-resistant first-degree relatives of type 2 diabetic patients. Diabetes 52 1182-1186.

Pi X, Yan C \& Berk BC 2004 Big mitogen-activated protein kinase (BMK1)/ERK5 protects endothelial cells from apoptosis. Circulation Research 94 362-369.
Sowers JR, Epstein M \& Frohlich ED 2001 Diabetes, hypertension, and cardiovascular disease: an update. Hypertension 37 1053-1059.

Stenvinkel P, Marchlewska A, Pecoits-Filho R, Heimburger O, Zhang Z, Hoff C, Holmes C, Axelsson J, Arvidsson S, Schalling M et al. 2004 Adiponectin in renal disease: relationship to phenotype and genetic variation in the gene encoding adiponectin. Kidney International 65 274-281.

Striker LJ, Doi T, Elliot S \& Striker GE 1989 The contribution of glomerular mesangial cells to progressive glomerulosclerosis. Seminars in Nephrology 9 318-328.

Suzaki Y, Yoshizumi M, Kagami S, Nishiyama A, Ozawa Y, Kyaw M, Izawa Y, Kanematsu Y, Tsuchiya K \& Tamaki T 2004 BMK1 is activated in glomeruli of diabetic rats and in mesangial cells by high glucose conditions. Kidney International 65 1749-1760.

Takeuchi Y, Yamauchi K, Nakamura J, Shigematsu S \& Hashizume K 2006 Angiotensin II regulates migration in mouse cultured mesangial cells: evidence for the presence of receptor subtype-specific regulation. Journal of Endocrinology 191 361-367.

Tozawa M, Iseki C, Tokashiki K, Chinen S, Kohagura K, Kinjo K, Takishita S \& Iseki K 2007 Metabolic syndrome and risk of developing chronic kidney disease in Japanese adults. Hypertension Research 30 937-943.

Weiss R, Dziura J, Burgert TS, Tamborlane WV, Taksali SE, Yeckel CW, Allen K, Lopes M, Savoye M, Morrison J et al. 2004 Obesity and the metabolic syndrome in children and adolescents. New England Journal of Medicine 350 2362-2374.

Weyer C, Funahashi T, Tanaka S, Hotta K, Matsuzawa Y, Pratley RE \& Tataranni PA 2001 Hypoadiponectinemia in obesity and type 2 diabetes: close association with insulin resistance and hyperinsulinemia. Journal of Clinical Endocrinology and Metabolism 86 1930-1935.

Yamaguchi H, Igarashi M, Hirata A, Sugae N, Tsuchiya H, Jimbu Y, Tominaga M \& Kato T 2004 Altered PDGF-BB-induced p38 MAP kinase activation in diabetic vascular smooth muscle cells: roles of protein kinase C-delta. Arteriosclerosis, Thrombosis, and Vascular Biology 24 2095-2101.

Yaturu S, Reddy RD, Rains J \& Jain SK 2007 Plasma and urine levels of resistin and adiponectin in chronic kidney disease. Cytokine 37 1-5.

Zhan Y, Kim S, Izumi Y, Izumiya Y, Nakao T, Miyazaki H \& Iwao H 2003 Role of JNK, p38, and ERK in platelet-derived growth factor-induced vascular proliferation, migration, and gene expression. Arteriosclerosis, Thrombosis, and Vascular Biology 23 795-801.

Received in final form 13 May 2009

Accepted 19 May 2009

Made available online as an Accepted Preprint 19 May 2009 